\title{
Anterior Part of the Calcarine Fissure
}

National Cancer Institute

\section{Source}

National Cancer Institute. Anterior Part of the Calcarine Fissure. NCI Thesaurus. Code C32102.

The anterior portion of a deep fissure or furrow on the medial surface of the cerebral cortex. 